\title{
Baseline spirometry parameters as predictors of airway hyperreactivity in adults with suspected asthma
}

Michael Peled ${ }^{1,2^{*}+}$, David Ovadya ${ }^{1,3 \dagger}{ }^{\dagger}$, Jennifer Cohn ${ }^{4 \dagger}$, Lior Seluk ${ }^{1}$, Teet Pullerits ${ }^{5}$, Michael J. Segel ${ }^{1,2 \dagger}$ and Amir Onn ${ }^{1+}$

\begin{abstract}
Background: Methacholine challenge tests (MCTs) are used to diagnose airway hyperresponsiveness (AHR) in patients with suspected asthma where previous diagnostic testing has been inconclusive. The test is time consuming and usually requires referral to specialized centers. Simple methods to predict AHR could help determine which patients should be referred to MCTs, thus avoiding unnecessary testing. Here we investigated the potential use of baseline spirometry variables as surrogate markers for AHR in adults with suspected asthma.
\end{abstract}

Methods: Baseline spirometry and MCTs performed between 2013 and 2019 in a large tertiary center were retrospectively evaluated. Receiver-operating characteristic curves for the maximal expiratory flow-volume curve indices (angle $\beta, F E V 1, F V C, F E V 1 / F V C, F E F_{50 \%}, F_{25}{ }_{25-75 \%}$ ) were constructed to assess their overall accuracy in predicting AHR and optimal cutoff values were identified.

Results: A total of 2983 tests were analyzed in adults aged $18-40$ years. In total, $14 \%$ of all MCTs were positive $(P C 20 \leq 16 \mathrm{mg} / \mathrm{ml})$. All baseline spirometry parameters were significantly lower in the positive group $(p<0.001)$. $\mathrm{FEF}_{50 \%}$ showed the best overall accuracy $(\mathrm{AUC}=0.688)$ and proved to be useful as a negative predictor when applying $\mathrm{FEF}_{50 \%} \geq 110 \%$ as a cutoff level.

Conclusions: This study highlights the role of $\mathrm{FEF}_{50 \%}$ in predicting AHR in patients with suspected asthma. A value of $\geq 110 \%$ for baseline $\mathrm{FEF}_{50 \%}$ could be used to exclude AHR and would lead to a substantial decrease in MCT referrals.

Keywords: Asthma, Bronchoconstrictor agents, Methacholine, Spirometry

\section{Background}

Methacholine challenge tests (MCTs) are used to detect and assess airway hyperreactivity (AHR). MCT has a negative predictive value of almost $90 \%$ for the provocative concentration causing a $20 \%$ fall (PC20) in forced expiratory volume in one second (FEV1) when PC20

${ }^{*}$ Correspondence: Michael.Peled@sheba.health.gov.il

${ }^{\dagger}$ Michael Peled, David Ovadya, Jennifer Cohn, Michael J. Segel and Amir Onn have contributed equally to this study

1 Institute of Pulmonary Medicine, Chaim Sheba Medical Center, Derech

Sheba st. 2, 52621 Ramat Gan, Israel

Full list of author information is available at the end of the article is greater than $16 \mathrm{mg} / \mathrm{ml} \mathrm{[1],} \mathrm{which} \mathrm{makes} \mathrm{it} \mathrm{useful} \mathrm{for}$ excluding the diagnosis of asthma, especially in the setting of equivocal spirometry findings, in the presence of typical asthma symptoms. Even though bronchial provocation tests are generally safe, they are time consuming and costly and often require a referral to a specialized testing center. Thus, it is of interest to minimize the amount of testing by predicting which patients will have a negative outcome in the MCT.

Several variables derived from the Maximal Expiratory Flow Volume (MEFV) curve have been suggested as possible predictors of AHR [2]. Two possible candidates are 
the forced expiratory flow rate between 25 and $75 \%$ of vital capacity $\left(\mathrm{FEF}_{25-75 \%}\right)$ and at $50 \%$ of vital capacity $\left(\mathrm{FEF}_{50 \%}\right)$. They are considered approximate measures of the flow in the peripheral airways and a reduction in either variable may therefore represent airflow limitation in the small airways $[3,4]$. A study analyzing AHR in asthmatics showed that $\mathrm{FEF}_{50 \%}$ percent of predicted was the best surrogate marker among all standard lung function variables to predict $\mathrm{PC} 20<4 \mathrm{mg} / \mathrm{ml}$ [2], including FEV1, forced vital capacity (FVC), FEV1/FVC, and $\mathrm{FEF}_{25-75 \%}$. No studies have investigated the predictive ability of these variables in a general population consisting of both asthmatics and healthy individuals.

In addition to the standard baseline parameters of spirometry, such as FEV1, FVC, FEV1/FVC, $\mathrm{FEF}_{25-75 \%}$ and $\mathrm{FEF}_{50 \%}$, a subjective visual assessment of concave patterns in the curvature of the descending limb of the MEFV may also suggest an obstructive process [5-7]. In 2005, the American Thoracic Society (ATS) and European Respiratory Society (ERS) task force stated that the first sign of airflow obstruction in the small airways on a spirogram is this concavity [8]. Objective measures to assess the curvilinearity of the MEFV curve have been proposed over the decades $[6,9,10]$. In 1988 Kapp et al. defined a new parameter, referred to as angle $\beta$, which characterized the shape of the MEFV curve by applying trigonometry to the conventional variables obtained from spirometry. The study further showed that the angle $\beta$ was significantly lower in individuals with asthma than in healthy individuals [11]. Unfortunately, no reference values have been established for an adult population and the angle $\beta$ therefore needs to be used with caution.

Since MCTs are expensive and time consuming, it is of importance to identify which individuals are highly unlikely of having a positive test beforehand. By finding an appropriate surrogate marker for AHR, physicians could already identify in a primary care setting which individuals have low probability of asthma and can be spared further testing.

We aimed to investigate the potential use of the angle $\beta$ and more standard spirometry parameters, such as FEV1 and FVC, as surrogate markers for predicting AHR in a general population, with the objective to elucidate novel ways of excluding AHR and subsequently avoid unnecessary MCTs.

\section{Methods}

\section{Setting and study participants}

This cross-sectional study was based on MCTs performed at the Institute of Pulmonology at Sheba medical center, Israel.

Data from study participants between 18 and 40 years of age who had undergone MCTs between 2013 and 2019 were included in the analysis. Participants were referred to MCT due to symptoms suggestive of asthma where a previous test, such as exercise challenge test or reversibility testing, had been inconclusive, in accordance with the GINA guidelines for asthma diagnosis [12].

\section{Design}

The dataset was randomly split into two cohorts, $75 \%$ were assigned to the derivation cohort $(n=2237)$ and $25 \%$ were included in the validation cohort $(n=746)$. The validation cohort was used to evaluate if the predictive models obtained in the derivation cohort perform similarly for a separate dataset (internal validation).

The following variables were obtained from the dataset and used for analysis: gender, age, weight (kg), height $(\mathrm{cm})$, forced vital capacity (FVC), forced expiratory volume in $1 \mathrm{~s}\left(\mathrm{FEV}_{1}\right)$, peak expiratory flow rate (PEFR), forced expiratory flow at $50 \%$ of forced vital capacity $\left(\mathrm{FEF}_{50 \%}\right)$, Forced expiratory flow at $25-75 \%$ of forced vital capacity $\left(\mathrm{FEF}_{25-75 \%}\right)$, the methacholine provocation concentration resulting in a $20 \%$ fall in $\mathrm{FEV}_{1}\left(\mathrm{PC}_{20}\right)$. Predicted values for $\mathrm{FVC}, \mathrm{FEV}_{1}$, Peak expiratory flow rate (PEFR), $\mathrm{FEF}_{25-75 \%}$, and $\mathrm{FEF}_{50 \%}$ were based on reference equations from the European Community of Coal and Steel (ECCS) [13], and were also analyzed according to the reference equations from the Global Lung Function Initiative (GLI) [14]. In addition, the following composite variables were calculated from extracted data: $\mathrm{BMI}(\mathrm{kg} /$ $\mathrm{m}^{2}$ ), $\mathrm{FEV}_{1} / \mathrm{FVC}$ ratio, FEV1/FVC \%predicted, FVC \%predicted, PEFR \%predicted, FEV1\%predicted, FEF $_{50 \%} \%$ predicted and $\mathrm{FEF}_{25-75 \%}$ \% predicted.

To quantify the shape of the maximum expiratory flowvolume curve (MEFV), the angle $\beta$ was calculated using equation in [11]: $\beta=180^{\circ}-\tan ^{-1}\left(\mathrm{PEFR}-\mathrm{FEF}_{50 \%} / 0.5 \times \mathrm{FVC}\right)+$ $\tan ^{-1}\left(\mathrm{FEF}_{50 \%} / 0.5 \mathrm{FVC}\right)$. All $\tan ^{-1}$ values were calculated in degrees and defined as the a ngle formed when projecting a line from the PEFR point to the mid flow point on the $\mathrm{X}$-axis $\left(\mathrm{FEF}_{50 \%}\right)$ and then connecting that point to the end point of the forced vital capacity (Additional file 1: Fig. S1).

Following ATS guidelines, a negative methacholine challenge result was defined as PC20 $>16 \mathrm{mg} / \mathrm{ml}$, while values of $\mathrm{PC} 20 \geq 4$ to $\leq 16 \mathrm{mg} / \mathrm{ml}$ were defined as borderline AHR [15]. For borderline cases the patient's symptoms were assessed by a physician and asthma treatment was initiated if deemed appropriate. For this reason, $\mathrm{PC} 20 \leq 16 \mathrm{mg} / \mathrm{ml}$ was set as the appropriate cut-off level for this study.

\section{Statistical analysis}

The mean values of continuous variables were compared using two-tailed t-test. Differences in frequencies for categorical variables were analyzed using 
Chi-squared test. The result for continuous variables was expressed as the mean $\pm \mathrm{SD}$ and categorical data was presented as number of observations and proportion of observations, in percent. For the derivation cohort, receiver operating curve (ROC) analysis was performed for all lung function parameters individually to determine the usefulness of each parameter for predicting a positive outcome in the MCT. The diagnostic performance of each variable was expressed as area under the curve (AUC). For the parameter with the best predictability, an optimal cut off point was established to optimize sensitivity and specificity. A multivariate analysis was performed using logistic regression; all available parameters were included. Using backward analysis, the number of variables was reduced until the model with the highest discriminative power was retained. ROC curve analysis was also used to verify diagnostic accuracy in the validation cohort. For the whole analysis, a $P$ value $\leq 0.05$ was considered statistically significant. Microsoft Excel version 16.35 was used to create composite variables and calculation of the angle $\beta$. Statistical analyses were performed using Graph Pad Prism version 8.4.0. and RStudio version 1.1.414.

\section{Results \\ Comparison of characteristics in derivation and validation cohort}

There was no significant difference in clinical characteristics at baseline between the derivation and validation cohorts (Table 1 according to ECCS equations, Additional file 1: Table S1 according to GLI equations and $\mathrm{z}$-scores; there is no reference for FEF50\% in the GLI, thus both FEF50\% and the angle $\beta$, which is based on FEF50\%, are not shown for GLI-based spirometry parameters). The distribution of gender was $81 \%$ males with a mean age of 24.2 years in both cohorts, and $14 \%$ of both cohorts had a positive outcome (PC20 $\leq 16 \mathrm{mg} /$ $\mathrm{ml}$ ) in the MCT. The male to female ratio was higher than the ratio in the general population because Sheba Medical Center accepts Israel Defense Forces recruits for asthma assessment. Importantly, gender did not affect the results of all the analyses below, according to subgroup analyses.

\section{Positive versus negative methacholine challenge test groups: baseline comparisons}

In order to determine which clinical parameters might have a predictive value, the derivation cohort was stratified depending on outcome in the MCT and comparisons between the two groups were conducted (Table 2 according to ECCS equations, Additional file 1: Table S2
Table 1 Demographics and pulmonary lung function characteristics at baseline for derivation and validation cohort

\begin{tabular}{|c|c|c|c|c|c|}
\hline & \multicolumn{2}{|l|}{$\begin{array}{l}\text { Derivation } \\
\text { cohort } \\
(n=2237)\end{array}$} & \multicolumn{2}{|c|}{$\begin{array}{l}\text { Validation } \\
\text { cohort }(n=746)\end{array}$} & \multirow[t]{2}{*}{$P$ value } \\
\hline & Mean & SD & Mean & SD & \\
\hline Age (years) & 24.20 & 3.67 & 24.20 & 3.60 & 0.62 \\
\hline Females & 434 (19\%) & - & $142(19 \%)$ & & $0.83^{*}$ \\
\hline Height (cm) & 173.53 & 8.42 & 173.87 & 8.50 & 0.34 \\
\hline Weight (kg) & 69.43 & 12.45 & 69.40 & 12.70 & 0.96 \\
\hline BMI $\left(\mathrm{kg} / \mathrm{m}^{2}\right)$ & 22.99 & 3.44 & 22.92 & 3.70 & 0.67 \\
\hline $\mathrm{FEV}_{1} / \mathrm{FVC}(\%$ pred) & 83.50 & 7.50 & 83.40 & 7.20 & 0.61 \\
\hline $\mathrm{FEV}_{1}$ (\%pred) & 94.50 & 11.30 & 94.40 & 11.30 & 0.92 \\
\hline $\mathrm{FEF}_{50 \%}(\%$ pred) & 87.80 & 22.80 & 87.60 & 22.30 & 0.82 \\
\hline FVC (\%pred) & 99.10 & 13.00 & 99.50 & 13.20 & 0.49 \\
\hline $\mathrm{FEF}_{25-75 \%}(\%$ pred $)$ & 86.30 & 23.10 & 87.10 & 23.70 & 0.43 \\
\hline $\mathrm{PC} 20 \leq 16 \mathrm{mg} / \mathrm{ml}(\%)$ & 305 (14\%) & - & 103 (14\%) & & $0.91^{*}$ \\
\hline Angle $\beta\left(^{\circ}\right)$ & 186.14 & 14.80 & 185.88 & 14.80 & 0.68 \\
\hline
\end{tabular}

BMI, Body Mass Index; $\mathrm{FEV}_{1}$, forced expiratory volume in $1 \mathrm{~s}$; FVC, forced vital capacity; $\mathrm{FEF}_{50 \%}$, forced expiratory flow at $50 \%$ of $\mathrm{FVC} ; \mathrm{FEF}_{25-75 \%}$, forced expiratory flow at $25-75 \%$ of FVC; PC20, Concentration of methacholine causing a $20 \%$ decrease in $\mathrm{FEV}_{1}$. Relative values of spirometry parameters are given as percentage of the predicted value (\% pred)

${ }^{*} P$ value from Chi-squared analysis

according to GLI equations and z-scores). The two groups had similar demographical characteristics. In contrast, all baseline spirometry parameters were significantly lower in the group with AHR (PC20 $\leq 16 \mathrm{mg} / \mathrm{ml})$ compared to the group without AHR according to ECCS equations (Table 2). However, FVC\% and FEF25-75\% were not significantly different between the two groups according to GLI equations (Additional file 1: Table S2).

\section{Predictive value of baseline lung function parameters}

Since all baseline lung function parameters were significantly different between the two groups according to ECCS equations, ROC analysis was performed on all spirometry variables in the derivation cohort, to test their predictive value for AHR. The area under the ROC curve (AUC) was calculated in order to assess the usefulness of each parameter for predicting positive outcome $(\mathrm{PC} 20 \leq 16 \mathrm{mg} / \mathrm{ml})$ in the MCT. Of all the tested parameters, $\mathrm{FEF}_{50 \%}$ \%predicted was identified as the best predictor, having the highest diagnostic accuracy of $\mathrm{AUC}=0.688$ (Fig. 1). Lower predictive values were found for $\mathrm{FEV}_{1} \%$ predicted, $\mathrm{FEV}_{1} / \mathrm{FVC} \%$ predicted and the angle $\beta$, with AUC of $0.657,0.651$ and 0.622 respectively (Fig. 1a, c, d). Lastly, FVC \% predicted and $\mathrm{FEF}_{25-75 \%} \%$ predicted were weaker predictors of AHR (Fig. 1b, f). Similar results were found for spirometry parameters 
Table 2 Comparison of demographics and baseline spirometry parameters in patients with positive versus negative methacholine challenge test in the derivation cohort

\begin{tabular}{|c|c|c|c|c|c|}
\hline & \multicolumn{2}{|c|}{$\begin{array}{l}\text { Methacholine } \\
\text { negative } \\
(\mathrm{n}=1932)\end{array}$} & \multicolumn{2}{|c|}{$\begin{array}{l}\text { Methacholine } \\
\text { positive } \\
(\mathrm{n}=305)\end{array}$} & \multirow[t]{2}{*}{$P$ value } \\
\hline & Mean & SD & Mean & SD & \\
\hline Age (years) & 24.10 & 3.65 & 24.50 & 3.80 & 0.16 \\
\hline Females & $367(19 \%)$ & - & $67(22 \%)$ & - & $0.22^{*}$ \\
\hline Height (cm) & 173.60 & 8.29 & 172.89 & 9.16 & 0.18 \\
\hline Weight (kg) & 69.53 & 12.26 & 68.77 & 13.50 & 0.36 \\
\hline $\mathrm{BMI}\left(\mathrm{kg} / \mathrm{m}^{2}\right)$ & 23.01 & 3.44 & 22.80 & 3.46 & 0.56 \\
\hline Smoking n (\%) ${ }^{* *}$ & & & & & 0.26 \\
\hline Non-smoker & $176(67)$ & & $42(67)$ & & \\
\hline Ex-smoker & $12(5)$ & & $6(9)$ & & \\
\hline Smoker & $75(28)$ & & $15(24)$ & & \\
\hline Total & $263(100)$ & & $63(100)$ & & \\
\hline $\mathrm{FEV}_{1} / \mathrm{FVC}$ ratio (\%pred) & 84.10 & 7.40 & 80.10 & 7.50 & $<0.01$ \\
\hline $\mathrm{FEV}_{1}$ (\%pred) & 95.40 & 11.00 & 89.10 & 11.70 & $<0.01$ \\
\hline $\mathrm{FEF}_{50 \%}(\%$ pred) & 89.80 & 22.80 & 75.10 & 18.00 & $<0.01$ \\
\hline FVC (\%pred) & 99.50 & 13.00 & 96.50 & 13.00 & $<0.01$ \\
\hline $\mathrm{FEF}_{25-75 \%}$ (\%pred) & 86.90 & 23.10 & 82.70 & 22.80 & $<0.01$ \\
\hline angle $\beta\left(^{\circ}\right)$ & 186.96 & 15.01 & 180.92 & 12.36 & $<0.01$ \\
\hline
\end{tabular}

Methacholine positive defined as $\mathrm{PC} 20 \leq 16 \mathrm{mg} / \mathrm{ml} ; \mathrm{PC} 20$, Concentration of methacholine causing a 20\% decrease in $\mathrm{FEV}_{1}$. BMI, Body Mass Index; $\mathrm{FEV}_{1}$, forced expiratory volume in $1 \mathrm{~s} ; \mathrm{FVC}$, forced vital capacity; $\mathrm{FEF}_{50 \%}$, forced expiratory flow at $50 \%$ of $\mathrm{FVC} \mathrm{FEF}_{25-75 \%}$, forced expiratory flow at $25-75 \%$ of FVC; Relative values of spirometry parameters are given as percentage of the predicted value (\% pred)

${ }^{*} P$ value from Chi-squared analysis

** Smoking status was available for 326 patients in the derivation cohort-263 from the MCT negative patients and 63 from the MCT positive patients

that were calculated according to GLI equations (Additional file 1: Fig. S2 and Fig. S3 for z-scores.).

\section{Threshold values for baseline spirometry parameters}

Since this study aims to identify potential baseline parameters that are useful for predicting individuals unlikely of displaying AHR, different cut-off values and their respective specificity and sensitivity were assessed in order to determine what values were clinically useful (Fig. 2). In Table 3, the sensitivity, specificity, positive predictive value (PPV) and negative predictive value
(NPV) for different cut-off levels of FEF50\% predicted are shown. When employing $\mathrm{FEF}_{50 \%} \%$ predicted $<120 \%$ as a cut-off level, a sensitivity and specificity of $99.1 \%$ and $10 \%$ respectively was obtained. When setting the cut-off level for $\mathrm{FEF}_{50 \%} \%$ predicted at $<110 \%$, the sensitivity and specificity were $96.6 \%$ and $19.3 \%$. To further illustrate the clinical implications of using $\mathrm{FEF}_{50 \%} \%$ predicted of $<110 \%$ as a threshold value, 395 (17.7\%) of all participants in the derivation cohort had a baseline value that was $\geq 110 \%$. Of those only $8(0.3 \%$ of derivation cohort) were false negatives, i.e. displayed AHR ( $\mathrm{PC} 20 \leq 16 \mathrm{mg} / \mathrm{ml})$, and of those only 6 showed significant AHR $(\mathrm{PC} 20<4 \mathrm{mg} / \mathrm{ml})$. This means approximately $17.7 \%$ of all MCTs can be avoided if $\mathrm{FEF}_{50 \%}$ \%predicted of $\geq 110 \%$ is used as an exclusion. Since the GLI equations are focused on outcomes recommended by the ATS/ERS guidelines (i.e. FEV1, FVC and FEV1/FVC), and thus do not include $\mathrm{FEF}_{50 \%}$, we have also assessed the ability of FEV1\%predicted to predict AHR (Additional file 1: Fig. S4 and Fig. S5 for z-scores, Additional file 1: Table S3). When setting the cut-off level for FEV1\%predicted at $<110 \%$, the sensitivity and specificity were $97.9 \%$ and $2.8 \%$, respectively, demonstrating reduced specificity compared with $\mathrm{FEF}_{50 \%}$ \%predicted. In addition, only 61 (2\%) of all participants in the derivation cohort had a baseline FEV1 value that was $\geq 110 \%$. Of those 7 were false negatives, i.e. displayed AHR $(\mathrm{PC} 20 \leq 16 \mathrm{mg} / \mathrm{ml})$, and of those 5 showed significant AHR $($ PC2 $<<\mathrm{mg} / \mathrm{ml})$, again demonstrating that FEV1 has reduced predictive value compared with $\mathrm{FEF}_{50 \%}$.

\section{Logistic regression model}

To create a model that combines several parameters and to detect possible confounding variables, backwards logistic regression was performed with the relevant variables.

A predictive model combining $\mathrm{FEF}_{50 \%}$ \%predicted with the angle $\beta$ and $\mathrm{FEF}_{25-75 \%}$ \%predicted yielded the highest discriminative power, with an $\mathrm{AUC}=0.72$ (Fig. 3). The diagnostic accuracy of this model outperforms all single parameter models proposed above. These three baseline parameters were associated with methacholine responsiveness independently of FEV $1 \%$ predicted, FVC \% predicted and FEV1/FVC ratio. The linear combination of the three parameters is depicted in the following equation: the probability for positive

$$
\operatorname{MCT} 16=\frac{1}{1+e^{0.69+4.3 \times\left(F E F_{50 \%} \% \text { predicted }\right)-0.02 \times \text { Beta_angle }+0.86 \times\left(F E F_{25 \%}-75 \% \% \text { predicted }\right)}}
$$


(See figure on next page.)

Fig. 1 Receiver operating characteristics (ROC) curve for; a baseline forced expiratory volume in $1 \mathrm{~s}$, FEV1\%predicted; b forced vital capacity, FVC \%predicted; c FEV1/FVC; d angle $\beta$; e forced expiratory flow at 50\% of FVC, FEF50\% \%predicted; f forced expiratory flow at 25-75\% of FVC, FEF $25-75 \%$ \% predicted in the derivation cohort as predictors of methacholine responsiveness. AUC = Area under the curve. Grey line represents the line of unity with $A \cup C=0.5$

\section{Validation cohort}

To assess if the previously produced results and predictive models hold true for a separate sample, replication of the analysis on all spirometry variables was performed on the validation cohort. Once again, $\mathrm{FEF}_{50 \%}$ \%predicted had the highest AUC of 0.692 (Additional file 1: Fig. S6) and was recognized as the best predictor of AHR. When applying a cut-off value of $110 \%$ for $\mathrm{FEF}_{50 \%}$ \% predicted in the validation cohort, the sensitivity was $98.1 \%$ and the specificity $20.1 \%$, with an accompanying NPV of 98.5 . Of all the participants in the validation cohort, $17.6 \%$ had an $\mathrm{FEF}_{50 \%}$ \%predicted over $110 \%$, meaning those study participants could have been exempt from going through a methacholine provocation. The logistic regression model once again showed a model combing $\mathrm{FEF}_{50 \%}$ \% predicted, angle $\beta$ and $\mathrm{FEF}_{25-75 \%}$ \%predicted provided the highest diagnostic accuracy of $\mathrm{AUC}=0.73$ (Additional file 1: Fig. S7). Overall, the results in the validation cohort were consistent with those from the derivation cohort.

\section{Discussion}

The aim of this study was to investigate baseline spirometry measures as potential predictive markers for absence of AHR in suspected asthmatics. The findings identified $\mathrm{FEF}_{50 \%}$ \%predicted as the best parameter to predict absence of AHR, while FVC \% and $\mathrm{FEF}_{25-75 \%}$ were poor predictors for a positive MCT. These results are in line with a previous study that found that $\mathrm{FEF}_{50 \%} \%$ predicted was the best parameter in order to predict degree of AHR in asthmatics, when $\mathrm{PC} 20 \leq 4 \mathrm{mg} / \mathrm{ml}$ was used as a cutoff for a positive outcome [2]. Another study found that asthmatic subjects with low $\mathrm{FEF}_{50 \%}$ \%predicted had significantly higher AHR, independently of FEV1, thus suggesting the contribution of the small airways to the severity of AHR [16]. The main difference and added novelty in our study is the inclusion of non-asthmatics and the potential of using the marker to exclude asthma at an early stage in the diagnostic process. The results indicate the potential of utilizing $\mathrm{FEF}_{50 \%}$ \%predicted in a clinical setting to inform physicians if there is any added diagnostic value in referring patients to MCTs. Unfortunately, there are no reference values for $\mathrm{FEF}_{50 \%}$ in the GLI equations, which are now considered as best practice standard, and our results imply that references for this important parameter should be considered in the future for GLI equations. Our analyses also imply that FVC \% and $\mathrm{FEF}_{25-75 \%}$ are poor predictors for a positive MCT. Importantly, both $\mathrm{FEF}_{25-75 \%}$ and $\mathrm{FEF}_{50 \%}$ are derived from FVC and thus are sensitive to errors in FVC measurement. Hence, normalization of these flows to FVC may allow improved prediction of AHR.

The discriminatory capability of $\mathrm{FEF}_{50 \%}$ does however have limitations with an overall diagnostic accuracy of $68.8 \%$ (AUC $=0.688$ ). This is mainly caused by a large amount of overlap between asthmatics and healthy individuals. This study however emphasizes its value as a negative predictor of AHR and suggests using a threshold value of $\geq 110 \%$ of baseline $\mathrm{FEF}_{50 \%}$ \%predicted to predict negative outcome in the MCT. When applying this cutoff value to the derivation cohort and validation cohort, almost a fifth of all tests could be avoided which in turn would save valuable time and money, both for health care providers and for individuals.

A model combining $\mathrm{FEF}_{50 \%}, \mathrm{FEF}_{25-75 \%}$ and angle $\beta$ was created by using backward logistic regression analysis on all parameters, and showed a slightly higher predictive ability than just using a single parameter, such as $\mathrm{FEF}_{50 \%}$ \%predicted. Since all three parameters have been suggested as markers of small airways obstruction, this model may indicate that obstruction in the small airways is in itself a predictor of AHR. This composite variable could easily be incorporated into spirometry software in the future.

There were several limitations in this study. Firstly, since this was a retrospective study, the follow-up of patients' clinical status was not taken into consideration. Since AHR can be present in other respiratory conditions such as chronic obstructive pulmonary disease (COPD), atopic individuals without respiratory symptoms and in smokers, some study participants could have been misdiagnosed $[15,17]$. Ideally, follow up of patients' response to medical treatment would have been desired. Assuming misdiagnosis only makes up a small part of our study sample, it would likely only add some background noise in the analysis and unlikely change the results significantly. The population in this study may be considered young, with an age range of 18-40 years. However, since this study is focused on asthma diagnosis, this age range is relevant. Indeed, many studies performed on adults with asthma show that the average age of asthma diagnosis in adults is at the early $30 \mathrm{~s}$ [18]. 




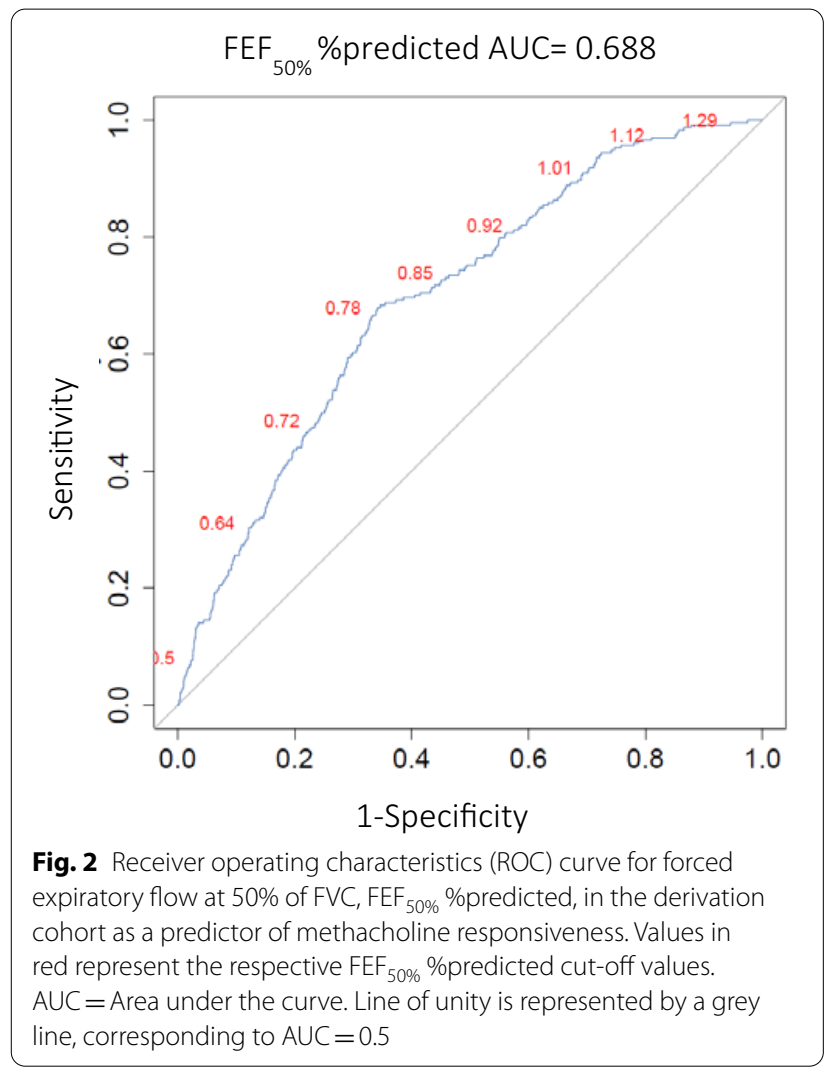

Table 3 Diagnostic performance of baseline $\mathrm{FEF}_{50 \%} \%$ predicted for different cut-off values, obtained by ROC analysis to predict methacholine responsiveness (PC20<16 mg/ml)

\begin{tabular}{lllll}
\hline Cut-off (\%) & Sensitivity (\%) & Specificity (\%) & PPV (\%) & NPV (\%) \\
\hline FEF $_{50 \%} \%$ predicted & & & \\
$<120$ & 99.10 & 10 & 11.40 & 99 \\
$<115$ & 97.80 & 14.50 & 11.80 & 98.30 \\
$<110$ & 96.60 & 19.30 & 12.30 & 97.90 \\
\hline
\end{tabular}

Sensitivity, specificity, positive predictive value (PPV), negative predicted value (NPV)

A major strength in this study is the large sample size and the use of a validation population to challenge the models. However, the method of random split-sampling, that was used for selecting the validation cohort is not the most desirable method for validation [19]. To further verify that the predictive models perform with the similar accuracy independently of sample population, it would have been preferable to use a validation cohort from an entirely different lung function clinic, to further prove the generalizability of the findings.

This study highlights the use of baseline $\mathrm{FEF}_{50 \%}$ \%predicted as a negative predictor of AHR, in adults with suspected asthma. By applying a threshold value of $\geq 110 \%$
FEF50\%predicted $+\beta$-angle + FEF25-75\% predicted AUC $=0.72$

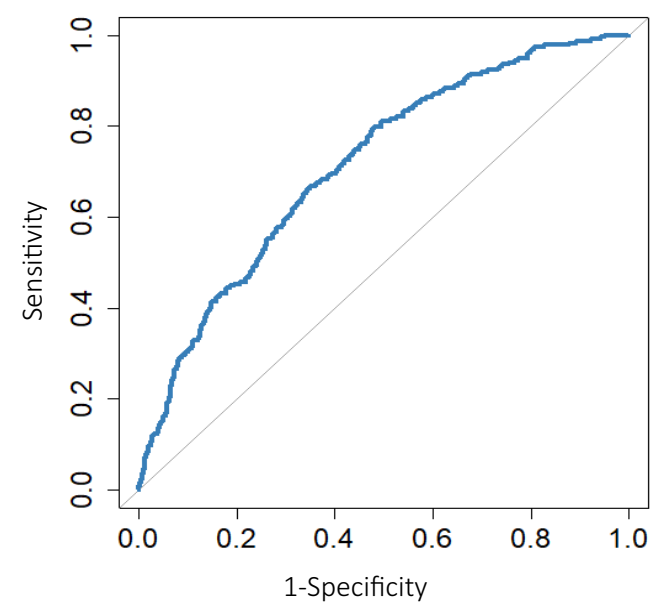

Fig. 3 Receiver operating characteristics (ROC) curve for model combining forced expiratory flow at 50\% of FVC, $\mathrm{FEF}_{50 \%} \%$ predicted, angle $\beta$ and forced expiratory flow at $25-75 \%$ of $\mathrm{FVC}, \mathrm{FEF}_{25-75 \%}$ $\%$ predicted as a predictor of methacholine responsiveness in the derivation cohort. $\mathrm{AUC}=$ Area under the curve. Line of unity is represented by a grey line, corresponding to $A U C=0.5$

of baseline $\mathrm{FEF}_{50 \%}$, almost a fifth of all MCTs may potentially be avoided. Prospective studies in the future would give better insight into the use of standard spirometry for predicting AHR and excluding asthma.

\section{Conclusions}

Baseline spirometry parameters may be used as tools for predicting airway hyper-responsiveness. FEF50\% proved to be useful as a negative predictor when applying FEF $50 \% \geq 110 \%$ as a cutoff level for exclusion of airway hyper-responsiveness, reducing the requirement for Methacholine Challenge Tests by approximately $20 \%$, and thus FEF50\% may be particularly useful to reduce the burden of unnecessary MCTs.

\section{Supplementary Information}

The online version contains supplementary material available at https://doi. org/10.1186/s12890-021-01506-6.

Additional file 1. Figure S1. Angle $\beta$ definition.Table 1s. Pulmonary lung function characteristics at baseline for primary and test cohort based on GLI equations. Table 2s. Comparison of baseline spirometry parameters in patients with positive versus negative methacholine challenge test in the primary cohort based on GLI equations. Figure S2. ROC-curves for derivation cohort according to GLI equations. Figure S3. ROC-curves for derivation cohort according to GLI equations with z-scores. Figure S4. ROC-curve FEV1 for the derivation cohort according to GLI equations. Figure S5. ROC-curve FEV1 z-score for the derivation cohort according to GLI equations. Table 3s. Diagnostic performance of baseline FEV1 \% predicted for different cut-off values, obtained by ROC analysis to predict methacholine responsiveness (PC20<16 mg/ml). Figure S6. ROC-curves 
for validation cohort. Figure S7. ROC curve of combined variable model for validation cohort.

\section{Acknowledgements}

Not applicable.

\section{Authors' contributions}

MP contributed to the conception, design of the work, interpretation of data and substantively revision. DO contributed to the design of the work, data acquisition, analysis and interpretation. JC contributed to the design of the work, data analysis, interpretation of data, and drafting the work. LS and TP substantially revised the manuscript. MJS and AO contributed to the conception and design of the work, and TP substantially revised the manuscript. All authors read and approved the final manuscript.

\section{Funding}

Funding was provided by University of Gothenburg.

\section{Availability of data and materials}

The datasets used and/or analysed during the current study are available from the corresponding author on reasonable request.

\section{Declarations}

\section{Ethics approval and consent to participate}

The study was conducted according to the Helsinki Declaration and was approved by the Institute Medical Ethics Committee of the Sheba Medical Center. Informed consent was waived by the Ethics Committee of the Sheba Medical Center as all data was anonymized.

\section{Consent for publication}

Not applicable.

\section{Competing interests}

The authors declare that they have no competing interests.

\section{Author details}

'Institute of Pulmonary Medicine, Chaim Sheba Medical Center, Derech Sheba st. 2, 52621 Ramat Gan, Israel. ${ }^{2}$ Sackler Faculty of Medicine, Tel-Aviv University, Tel-Aviv, Israel. ${ }^{3}$ Department of Respiratory Care and Rehabilitation, Chaim Sheba Medical Center, Ramat Gan, Israel. ${ }^{4}$ Faculty of Medicine, Sahlgrenska Academy, University of Gothenburg, Gothenburg, Sweden. ${ }^{5}$ Department of Asthma and Allergology, Sahlgrenska University Hospital, Gothenburg, Sweden.

Received: 7 January 2021 Accepted: 13 April 2021

Published online: 06 May 2021

\section{References}

1. Selvanathan J, Aaron SD, Sykes JR, Vandemheen KL, FitzGerald JM, Ainslie $\mathrm{M}$, et al. Performance characteristics of spirometry with negative bronchodilator response and methacholine challenge testing and implications for asthma diagnosis. Chest. 2020;158(2):479-90.
2. Kono Y, Soeda S, Okada Y, Hara H, Araki K, To M, et al. A surrogate marker of airway hyperresponsiveness in patients with bronchial asthma. Allergol Int. 2014;63(3):487-8.

3. Burgel PR. The role of small airways in obstructive airway diseases. Eur Respir Rev. 2011;20(119):023.

4. van den Berge M, ten Hacken NHT, Cohen J, Douma WR, Postma DS. Small airway disease in asthma and COPD: clinical implications. Chest. 2011;139(2):412-23.

5. Hyatt RE. Interpretation of pulmonary function tests a practical guide. In: Scanlon PD, Nakamura M, editors. Ovid Technologies I. 2nd ed. Philadelphia: Lippincott Williams \& Wilkins; 2003.

6. Mead J. Analysis of the configuration of maximum expiratory flowvolume curves. J Appl Physiol. 1978;44(2):156-65.

7. Wildhaber JH, Sznitman J, Harpes P, Straub D, Moller A, Basek P, et al. Correlation of spirometry and symptom scores in childhood asthma and the usefulness of curvature assessment in expiratory flow-volume curves. Respir Care. 2007;52(12):1744-52.

8. Pellegrino R, Viegi G, Brusasco V, Crapo RO, Burgos F, Casaburi R, et al. Interpretative strategies for lung function tests. Eur Respir J. 2005:26(5):948-68.

9. O'Donnell CR, Rose RM. The flow-ratio index: an approach for measuring the influence of age and cigarette smoking on maximum expiratory flow-volume curve configuration. Chest. 1990;98(3):643-6.

10. Zheng C-J, Adams AB, MCGrail MP, Marini JJ, Greaves IA. A proposed curvilinearity index for quantifying airflow obstruction. Respir Care. 2006;51(1):40.

11. Kapp MC, Schachter EN, Beck GJ, Maunder LR, Witek TJ Jr. The shape of the maximum expiratory flow volume curve. Chest. 1988;94(4):799-806.

12. Global Initiative for Asthma. Global strategy for asthma management and prevention, 2019. 2019 [cited 202013 February]. www.ginasthma.org.

13. Quanjer PH, Tammeling GJ, Cotes JE, Pedersen OF, Peslin R, Yernault JC. Lung volumes and forced ventilatory flows. Eur Respir J. 1993;6(Suppl 16):5-40.

14. Quanjer PH, Stanojevic S, Cole TJ, Baur X, Hall GL, Culver BH, et al. Multiethnic reference values for spirometry for the 3-95-yr age range: the global lung function 2012 equations. Eur Respir J. 2012;40(6):1324-43.

15. Guidelines for Methacholine and Exercise Challenge Testing-1999. Am J Respir Crit Care Med. 2000;161(1):309-29.

16. Telenga ED, van Den Berge M, Ten Hacken NHT, Riemersma RA, van Der Molen T, Postma DS. Small airways in asthma: their independent contribution to the severity of hyperresponsiveness. Eur Respir J. 2013;41(3):752

17. Borak J, Lefkowitz RY. Bronchial hyperresponsiveness. Occup Med 2015;66(2):95-105.

18. Lee LA, Bailes Z, Barnes N, Boulet LP, Edwards D, Fowler A, et al. Efficacy and safety of once-daily single-inhaler triple therapy (FF/UMECNI) versus FF/ II in patients with inadequately controlled asthma (CAPTAIN): a double-blind, randomised, phase 3A trial. Lancet Respir Med. 2021;9(1):69-84.

19. Steyerberg EW, Harrell FE Jr. Prediction models need appropriate internal, internal-external, and external validation. J Clin Epidemiol. 2016;69:245-7.

\section{Publisher's Note}

Springer Nature remains neutral with regard to jurisdictional claims in published maps and institutional affiliations. 